\title{
Effects of Several Variable Factors on the Isotope Ratio by HRGC-MS
}

\author{
Masayoshi Sawamura, ${ }^{1, \dagger}$ Atsushi Satake, ${ }^{1,2}$ Takao Ueno, ${ }^{1}$ Akitoshi Une, ${ }^{1}$ \\ and Hiroyuki UKeDA ${ }^{1}$ \\ ${ }^{1}$ Department of Bioresources Science, Faculty of Agriculture, Kochi University, \\ B-200 Monobe, Nankoku, Kochi 783-8502, Japan \\ ${ }^{2}$ Nagaoka Perfumery Co., Ltd., 3-30, 1-chome, Itsukaichi City, Osaka 567-0005, Japan
}

Received March 26, 2003; Accepted September 27, 2003

In the isotope ratio (Ir) analysis using GC-MS, several variable factors in sampling incidental to any food analysis were investigated for yuzu fruit. The Irs of ten monoterpene hydrocarbons in yuzu essential oils from each of six fruiting positions of three trees were measured. The sign test following $t$-test of all the $\mathrm{Ir}$ values demonstrated that there was no significant difference between both sampling years of 2001 and 2002. There was also no significant variation in the Ir values among the three trees and six fruiting positions in the individual two years.

Key words: isotope ratio analysis; sampling variations; HRGC/MS; monoterpene hydrocarbon

A determination of the isotope values of constituents is gaining increasing importance, especially in view of the increased demand in the fragrance and food industries for the authenticity control and origin determination of the production of essential oils and foods. ${ }^{1-3)}$ Recently, many sensational articles have been reported on dishonest designations of raw foods, since the JAS (Japanese Agricultural Standards) were revised on July 2000. The authors ${ }^{4)}$ have developed a specific and convenient method for characterization of yuzu (Citrus junos Tanaka) fruits produced in different districts by the isotope ratio of monoterpene hydrocarbons with HRGC-MS. This method will be applicable to several cases such as differentiation of the quality, evaluation of genuineness of vegetable products from various producing districts, and classification of the species. It is noticed that this analytical method will be useful for chemical evaluation of agricultural products, in addition to DNA analysis. ${ }^{5,6)}$ The authors ${ }^{7,8)}$ have also reported successful results on the discrimination of commercial citrus essential oils of different origins, and the accuracy of the $\mathrm{Ir}$ method using ${ }^{13} \mathrm{C}$-labeled compounds. There remain, however, some questions about samplings from the fundamental scope. In order to normalize this method, the variations or individual differences which each material substantially owns should be further investigated. This paper concerns the effects of variable factors involved in fruit samples regarding the isotope ratio analysis.

Three yuzu trees (13- to 15-years age) were selected at random among a number of yuzu trees under the usual cultivation in the field of Kochi Fruit Tree Experimental Station, Kochi. The experiments were done from the following three viewpoints: (1) annual variations between 2001 and 2002; (2) variations among trees; (3) variations between fruiting positions on the trees. All the samplings were done from these three trees in November 2001 and 2002. The six fruiting positions on each tree were as follows: top, inside, and the four sides of East, West, South, and North around equatorial canopy of the tree. The cold-pressed peel oil (CPO) of about $2 \mathrm{~kg}$ of each sample was prepared according to the usual method. ${ }^{9)}$ The yield of CPO was $0.10-0.16 \mathrm{~g} / 100 \mathrm{~g}$ of fresh fruit, and $0.34-0.59 \mathrm{~g} / 100 \mathrm{~g}$ of flavedo. Each CPO sample was kept at $-25^{\circ} \mathrm{C}$ until needed for analysis. Gas chromatography-mass spectrometry (GC-MS) was done with a Shimadzu GC-17A linked to a Shimadzu QP5000. The GC column was a DB-Wax fused silica capillary $(60 \mathrm{~m} \times 0.25 \mathrm{~mm}$ i.d., $0.25 \mu \mathrm{m}$ film thickness; J \& W Scientific, Folsom, CA, U.S.A.) The analytical conditions of GC-MS and column temperature were the same as those of the previous paper. ${ }^{4)}$ The isotope ratio (Ir) of the selected monoterpene hydrocarbons in CPO, $m / z 137 / 136$, was measured by selected-ion monitoring (SIM). Those compounds analyzed were $\alpha$-pinene, $\beta$ pinene, sabinene, myrcene, $\alpha$-phellandrene, $\alpha$-terpinene, limonene, $\beta$-phellandrene, $\gamma$-terpinene, and terpinolene. All the measurements were triplicated. The statistical treatments, $t$-test and sign test, were done as well as described before. ${ }^{4,10)}$

A sign test was applied to the following evaluation. The Irs of ten monoterpene hydrocarbons in the CPOs from each of the six fruiting positions of three trees were measured in triplicate in an individual year. All the data obtained on each monoterpene hydrocarbon were first treated with the $t$-test between 2001 and 2002, and then the resulting data were analyzed by a sign test. ${ }^{4}$ ) The

\footnotetext{
$\dagger$ To whom correspondence should be addressed. Tel: +81-88-864-5184; Fax: +81-88-864-5200; E-mail: sawamura@cc.kochi-u.ac.jp
} 
Table 1. Analysis of Annual Variations by Sign Test Based on the Ir Values in Yuzu Essential Oils

\begin{tabular}{ll}
\hline \hline Fruiting position & $S^{\mathrm{a}}$ \\
\hline Top & 3.0 \\
Inside & 2.5 \\
East side & 2.5 \\
West side & 1.5 \\
South side & 2.0 \\
North side & 2.5 \\
\hline
\end{tabular}

a Sign values. $P<0.05(S=1.0107, \mathrm{n}=10)$; the parameter (n) was ten monoterpene hydrocarbons.

The sampling was done in November of 2001 and 2002. Fruits of each fruit position were collected from three trees to prepare cold-pressed oil from individual years. The weight percent measurement of the ten monoterpene hydrocarbons in oil sample for each fruiting position was triplicated, and then the data of each position were analyzed by $t$-test between 2001 and 2002 . Finally, the results of the $t$-test were applied for the sign test.
Table 2. Analysis of Tree Variations by $t$-Test Based on the Ir Values in Yuzu Essential Oils

\begin{tabular}{lccc}
\hline \hline Tree & $\mathrm{P}_{1}$ & $\mathrm{P}_{2}$ & $\mathrm{P}_{3}$ \\
\hline $\mathrm{P}_{1}$ & 0 & 0 & 0 \\
$\mathrm{P}_{2}$ & 0 & 0 & 0 \\
$\mathrm{P}_{3}$ & & \\
\hline+ and - : Significant, 0: not significant, $P<0.05$. \\
Samples were collected from $\mathrm{P}_{1}, \mathrm{P}_{2}$, and $\mathrm{P}_{3}$ trees, respectively. The Ir values \\
of each monoterpene hydrocarobon are composed of the triplicated values \\
from 6 fruiting positions of each tree. \\
The $t$-test was done for each monoterpene hydrocarbon among $\mathrm{P}_{1}, \mathrm{P}_{2}$, and \\
$\mathrm{P}_{3}$. The result shows either year of 2001 and 2002.
\end{tabular}

Table 3. Ir Values of Each Fruiting Position and Least Significant Difference Test

\begin{tabular}{|c|c|c|c|c|c|c|c|c|c|c|}
\hline \multirow{2}{*}{$\begin{array}{l}\text { Fruiting } \\
\text { position }\end{array}$} & \multicolumn{10}{|c|}{ Monoterpene hydrocarbons } \\
\hline & $\alpha$-pinene & $\beta$-pinene & sabinene & myrcene & $\alpha$-phellandrene & $\alpha$-terpinene & limonene & $\beta$-phellandrene & $\gamma$-terpinene & terpinolene \\
\hline Top & 11.30 & 11.40 & 11.42 & 11.38 & 11.37 & 11.25 & 11.49 & 11.18 & 11.23 & 11.47 \\
\hline Inside & 11.29 & 11.37 & 11.33 & 11.35 & 11.35 & 11.36 & 11.50 & 11.17 & 11.24 & 11.38 \\
\hline East side & 11.28 & 11.40 & 11.50 & 11.34 & 11.37 & 11.31 & 11.51 & 11.18 & 11.23 & 11.34 \\
\hline West side & 11.28 & 11.42 & 11.53 & 11.34 & 11.34 & 11.35 & 11.50 & 11.17 & 11.23 & 11.43 \\
\hline South side & 11.29 & 11.40 & 11.36 & 11.37 & 11.38 & 11.38 & 11.52 & 11.17 & 11.24 & 11.36 \\
\hline North side & 11.25 & 11.42 & 11.32 & 11.37 & 11.34 & 11.47 & 11.46 & 11.15 & 11.21 & 11.38 \\
\hline$\Delta^{\mathrm{a}}$ & 0.05 & 0.05 & 0.21 & 0.04 & 0.04 & 0.22 & 0.06 & 0.03 & 0.03 & 0.13 \\
\hline L.s.d. ${ }^{b}$ & 0.06 & 0.08 & 0.65 & 0.06 & 0.06 & 0.23 & 0.07 & 0.04 & 0.04 & 0.19 \\
\hline
\end{tabular}

a Maximum difference.

b $P<0.05$.

The Ir values of each monoterpene hydrocarbon are means of triplicated values for each fruiting position collected from three trees.

The result for the year 2002 is shown here.

results are shown in Table 1 . In the case of ten parameters $(n=10)$, i.e., ten monoterpene hydrocarbons, the significant level $(P<0.05)$ is below 1.0107. It was demonstrated that there was no significant difference between the two sampling years of 2001 and 2002. An annual variation factor, in other words, will not significantly affect the analysis based on the Ir ratio, even if fruits are sampled from any position on a tree.

All the Ir values of ten monoterpene hydrocarbons from all the fruiting positions on each tree were used for the $t$-test among the three trees. The result is shown in Table 2. There was no significant difference in the Ir values between the trees $(P<0.05)$. Thus, it suggests that any tree in a given area is allowed to be sampled without significant variation.

The Ir values of ten monoterpene hydrocarbons from each fruiting position on the three trees in 2002 were analyzed by the least significant difference test, as shown in Table 3. No significant difference $(P<0.05)$ among all the fruiting positions of each compound was seen. The result for 2001 was the same as that for 2002 .

In conclusion, it is suggested that the data obtained from this Ir ratio analysis, which is used for discriminating producing districts or genuineness of crops, are independent upon common variations incidental to samplings as long as the samples are collected in the same area. Many common components of foods usually fluctuate among individual samples. It is expected that this analysis will be used widely for judgment of the characteristics of agricultural products.

\section{Acknowledgments}

The authors appreciate the help of Mr. M. Tanaka of Kochi Fruit Tree Experimental Station, Kochi Prefectural Agriculture Research Center for kindly providing the yuzu samples. This study was partly done by the aid of the Kiei-kai Research Foundation in 2002.

\section{References}

1) Faber, B., Krause, B., Dietrich, A., and Mosandl, A., Gas chromatography-isotope ratio mass spectrometry in the analysis of peppermint oil and its importance in the authenticity control. J. Essent. Oil Res., 7, 123-131 (1955).

2) Hener, U., Faulhaber, S., Kreis, P., and Mosand1, A., On the authenticity evaluation of balm oil (Melissa offici- 
nalis L.). Pharmazie, 50, 60-62 (1995).

3) Faulhaber, S., Hener, U., and Mosandl, A., GC-IRMS analysis of mandarin essential oils. $2 \cdot \delta^{13} \mathrm{C}_{\mathrm{PDB}}$ values of characteristic flavor components. J. Agric. Food Chem., 45, 4719-4725 (1997).

4) Sawamura, M., Ito, T., Une, A., Ukeda, H., and Yamasaki, Y., Isotope ratio by HRGC-MS of Citrus junos Tanaka (yuzu) essential oils: $\mathrm{m} / z$ 137/136 of terpene hydrocarbons. Biosci. Biotechnol. Biochem., 65, 2622-2629 (2001).

5) Hino, A., Latest detecting technology of genetically modified agricultural products. The Food Industry (in Japanese), 45, 18-24 (2002).

6) IAI Center for Food Quality, Labeling, and Consumer Services, 2002, http://maff.go.jp/sogo_shokuryo/jas/ manual00.htm
7) Satake, A., Une, A., Ueno, T., Ukeda, H., and Sawamura, M., Isotope ratio analysis by GC-MS and application to citrus essential oils. Abstracts of International Symposium on the Chemistry of Essential Oils, Terpenes, and Aromatics (Tokushima, Japan), 10-12 (2002).

8) Satake, A., Une, A., Ueno, T., Ukeda, H., and Sawamura, M., Isotope ratio analysis by HRGC-MS of monoterpene hydrocarbons from citrus essential oils. Biosci. Biotechnol. Biochem., 67, 599-604 (2003).

9) Sawamura, M., and Kuriyama, T., Quantitative determination of volatile constituents in the pummelo (Citrus grandis Osbeck forma Tosa-buntan). J. Agric. Food Chem., 36, 567-569 (1988).

10) Okuno, T., "Oyo Tokei Handbook" (in Japanese), Yokendo, Tokyo, pp. 70-72 (1986). 